Article

\title{
Design of a Multi-Band Microstrip Textile Patch Antenna for LTE and 5G Services with the CRO-SL Ensemble
}

\author{
Carlos Camacho-Gomez, Rocio Sanchez-Montero *(1), Diego Martínez-Villanueva, \\ Pablo-Luís López-Espíi and Sancho Salcedo-Sanz \\ Department of Signal Processing and Communications, Escuela Politécnica Superior, Universidad de Alcalá, \\ Campus Universitario, Ctra. de Madrid a Barcelona km 33.600, 28805 Alcalá de Henares, Spain; \\ carlos.camacho@uah.es (C.C.-G.); diego.martinezv@edu.uah.es (D.M.-V.); pablo.lopez@uah.es (P.-L.L.-E.); \\ sancho.salcedo@uah.es (S.S.-S.) \\ * Correspondence: rocio.sanchez@uah.es; Tel.: +34-91-8856660
}

Received: 17 January 2020; Accepted: 7 February 2020; Published: 9 February 2020

Featured Application: A novel textile U-shaped with concentric annular slot antenna prototype for LTE and 5G services has been described. In the ground plane, a meander slot has been introduced to reduce the antenna dimensions. A new multi-method metaheuristic algorithm, the Coral Reefs Optimization with Substrate Layer CRO-SL, has been used to optimize the antenna parameters and improve its performance in the frequency bands of interest.

Abstract: A textile multi-band antenna for LTE and 5G communication services, composed by a rectangular microstrip patch, two concentric annular slots and a U-Shaped slot, is considered in this paper. In the ground plane, three sleeved meanders have been introduced to modify the surface current distribution, leading to a bandwidth improvement. The U-Shaped slot, the dual circular slots, and the meanders shape have been optimized by means of the Coral Reefs Optimization with Substrate Layer algorithm (CRO-SL). This population-based meta-heuristic approach is a kind of ensemble algorithm for optimization (multi-method), in which different search operators are considered within the algorithm. We show that the CRO-SL is able to obtain a robust multi-band textile antenna, including LTE and 5G frequency bands. For the optimization process, the CRO-SL is guided by means of a fitness function obtained after the antenna simulation by a specific simulation software for electromagnetic analysis in the high frequency range.

Keywords: antenna design; constrained optimization problems; coral reefs optimization algorithm; meta-heuristics

\section{Introduction}

In the last decade, a large variety of wireless enabled portable devices such as smartphones, tablets or laptops have been introduced. The implementation of new mobile technologies further increases the bandwidth requirements of wireless systems in order to cover recently allocated LTE and $5 \mathrm{G}$ frequency bands [1]. Recent research works have allowed us to develop the design of antennas using textile materials in the substrate, leading to devices called "wearable antennas" [2]. One of the main advantages of the antennas based on textile materials is that they can be manufactured using smart fabric and interactive textile systems [3], in which unobtrusive integration of electronic components increases functionality of the garment $[4,5]$.

Recently, the implementation of different kind of antennas in wearables has been massive [6-9]. Microstrip patch antennas are frequently used in textile materials because of their many advantages, 
such as low profile, light weight, and conformity. However, these kind of antennas suffer from important issues in their design process (precise value and model of fabric dielectric constant for simulations, difficulty to glue metallic parts to textile materials, bending and moisture influence in antenna performance, etc.), causing severe limitations in their practical applications. This fact is even more dramatic in the frequency bands of modern communication systems based on LTE and 5G technologies. The number of parameters to be tuned in order to make the antenna feasible for working in LTE and 5G applications is usually very high. In these cases, classical optimization methods are no longer suitable, and the employment of advanced optimization algorithms (mainly meta-heuristic approaches, among others) has been shown to be very useful for antenna design [10-14].

In this paper, we propose a new model of microstrip textile patch antenna, a multi-band device that can be tuned for LTE and 5G services, among others. Specifically, the proposed antenna is composed by a rectangular microstrip patch with two concentric annular slots and a U-Shaped slot, with sleeved meanders introduced in the ground plane to modify the surface current distribution, leading to a bandwidth improvement [15-17]. This original shape allows the antenna to work accurately in several frequency bands, including LTE and 5G communication services. On the other hand, this specific shape also leads to a hard optimization problem, with a high number of real variables and constraints to be taken into account. Moreover, the proposed antenna has been simulated considering a wearable substrate, which makes the direct designing process even more difficult.

A meta-heuristic algorithm for optimization is then considered in order to obtain a good design of the antenna, with excellent properties of bandwidth in all the considered frequency bands. Therefore, we propose to use a version of the Coral Reefs Optimization (CRO) algorithm [18] —in this case, the version with the substrate layer (CRO-SL) approach [19]. The CRO is an evolutionary type algorithm which simulates all the processes occurring in a real coral reef in order to carry out the optimization of a given system (the textile antenna considered in this work in this case). The CRO-SL version has been successfully applied to a number of optimization problems [19], and it is able to combine different search patterns or strategies within a single population of potential solutions. In this case, we will show how this optimization scheme is able to obtain excellent results in the optimization process of the proposed antenna, tuning it for its use in LTE and 5G communication systems. In the experimental section of the paper, we detail the antenna design process and its simulation with specific software in order to evaluate the potential of the CRO-SL in this design problem.

The rest of the paper is structured in the following way: the next section presents in detail the proposed antenna design, characteristics, and variables to be optimized. Section 3 describes the CRO-SL algorithm used to optimize the textile antenna for LTE and 5G systems. Section 4 shows the experiments carried out to optimize the antenna, and the results obtained in simulation of the optimized device. Finally, Section 5 closes the paper with some final remarks on the research carried out in this paper.

\section{Antenna Model}

The proposed microstrip patch antenna is shown in Figure 1. It combines several key features to provide the desired operational performance at different frequencies, including LTE and 5G bands. Specifically, the proposed design comprises a rectangular microstrip patch with two concentric annular slots. Each ring has four spikes within it. This type of patch antenna is inspired by different works previously presented in the literature [20-24]. Additionally, the design contains a U-shaped aperture of rectangular slots to obtain the resonant frequency for the LTE band. U-slot patch antennas are well known mainly for their wide-band characteristics and are capable of providing other advantages, including dual band and triple-band operations, due to their ability to be implemented with other patch antenna shapes, such as circular, triangular, or rectangular shapes [25]. The proposed antenna is completed with three meander slots at the bottom of the ground plane, according to the study in reference [26]. Table 1 shows the variables involved in antenna design and the variable ranges considered in this case. 


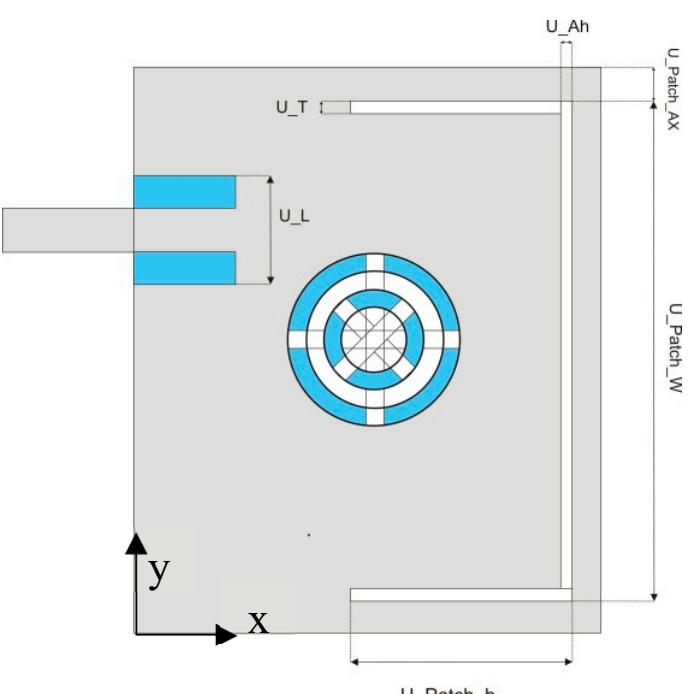

(a)

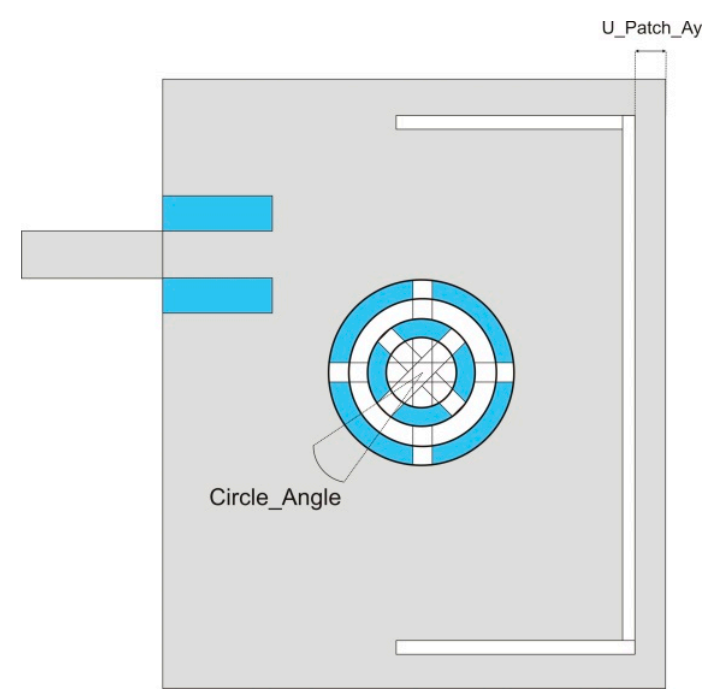

(c)

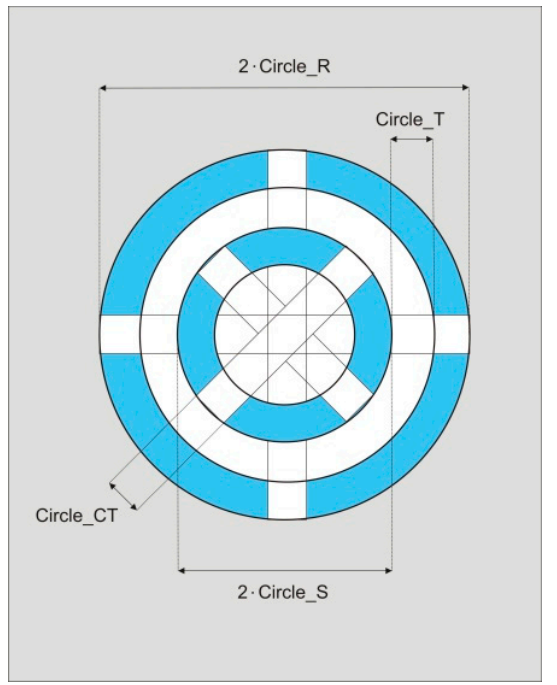

(b)

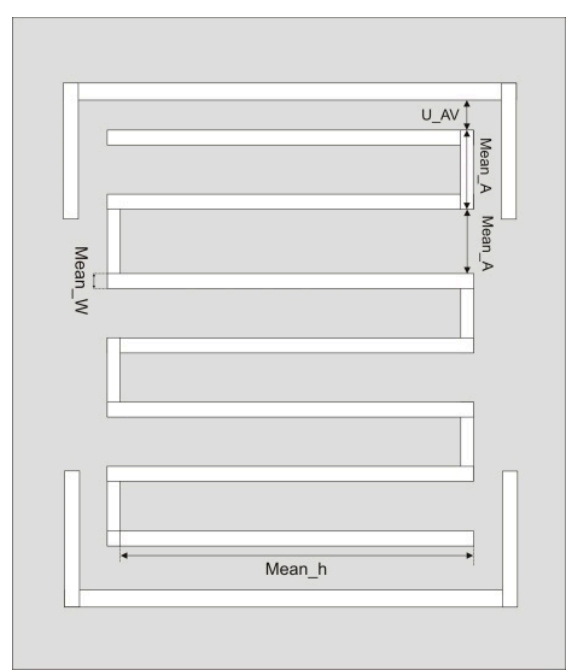

(d)

Figure 1. Variables description of the proposed antenna. (a) Antenna top view U-shaped variable description; (b) antenna top view the annular patch variable description; (c) detail description of the variables in the top view of the antenna that have been used in the optimization process; (d) antenna ground plane.

Note that the optimization of the proposed antenna in order to be operational in the desired frequencies is a hard problem in which metaheuristic algorithms can obtain good results. Note also that the objective function must be calculated starting from the antenna simulation for a given set of antenna parameters. Thus, the hybridization of a simulation software with a meta-heuristic algorithm is necessary to tackle the optimization of this antenna. Specifically, the CRO-SL algorithm will be used as optimizer, since its characteristics of multi-method with different search operators may work fine in this problem. The CRO-SL will be hybridized with the CST simulation software in order to obtain the performance of each antenna in the CRO-SL evolution. 
Table 1. Definition of the variables to optimize in the design of the proposed antenna (see Figure 1 for details).

\begin{tabular}{|c|c|}
\hline Variable & Range \\
\hline \multicolumn{2}{|c|}{ Antenna top view } \\
\hline U_T & {$[1,5]$} \\
\hline U_Patch_h & {$[1, \mathrm{Lp}]$} \\
\hline U_Patch_AY & {$[0.5,(\mathrm{Wp}-2$ Circle_R $) / 2]$} \\
\hline U_Patch_AX & [0.5,Lp/2-U_Patch_W-Circle_R] \\
\hline U_Ah & [1,(Wp-7Mean_A-8Mean_W-2U_T)/2] \\
\hline $\bar{U} \_L$ & {$[0.5, \mathrm{Wp}]$} \\
\hline U_Patch_W & {$[1,5]$} \\
\hline Circle_R & {$[11, \mathrm{Wp} / 2]$} \\
\hline Circle_Angle & {$[0.5,180]$} \\
\hline Circle_S & {$[3,5]$} \\
\hline Cirlce_CT & {$[1,5]$} \\
\hline Circle_T & {$[3,5]$} \\
\hline \multicolumn{2}{|c|}{$\mathrm{Lp}=60 \mathrm{~mm} ; \mathrm{Wp}=90 \mathrm{~mm}$} \\
\hline \multicolumn{2}{|c|}{ Antenna ground plane } \\
\hline Mean_W & {$[1,2.7]$} \\
\hline Mean_A & {$[1,10]$} \\
\hline Mean_h & {$[1, \mathrm{Lp}]$} \\
\hline U_AV & [1,(Lp-Mean_h-2U_T)/2] \\
\hline
\end{tabular}

\section{Antenna Optimization: the CRO-SL Algorithm}

A multi-method ensemble CRO-SL is the algorithm used to optimized the proposed antenna. This algorithm is an advanced version of a basic original version of the CRO [18]. The CRO is an evolutionary-type algorithm in which the search operators are based on the processes occurring in a coral reefs, including reproduction, fight for space, or depredation [19]. The pseudocode of the original $\mathrm{CRO}$ is shown below, with the different CRO phases (reef initialization and reef formation), along with all the operators applied to guide the search.

Table 2. Description of the pseudo-code for the Coral Reefs Optimization (CRO) algorithm.

\begin{tabular}{cl}
\hline Algorithm Step & \multicolumn{1}{c}{ Pseudo-Code for the CRO Algorithm } \\
\hline 1 & Require: CRO algorithm parameters \\
2 & Ensure: An optimal feasible individual (best antenna design) \\
3 & Initialize the algorithm and CRO parameters \\
4 & for each iteration of the simulation do \\
5 & Update values of CRO parameters: predation probability, etc. \\
6 & Broadcast spawning and Brooding operators \\
7 & Settlement of new corals \\
8 & Predation process \\
9 & Evaluate the new population in the coral reef \\
10 & end for \\
11 & Return: the best individual (final solution) from the reef \\
\hline
\end{tabular}

The CRO-SL (Coral Reef Optimization with Substrate Layers) is an improved version of the CRO [19]. It consists of a multi-method ensemble for optimization [27], with extremely good search capabilities for optimization tasks. The CRO-SL has the same algorithmic structure than the basic $\mathrm{CRO}$, but several substrate layers are defined in the algorithm, each one implementing a different search procedure or strategy. In fact, the CRO-SL is an ensemble approach which promotes competitive co-evolution, where each substrate layer may represent different processes (different models, search operators, problem's parameters, etc.), though the multi-method version, in which the 
substrate layers represent different search operators, has been the most successful version. Details on the overall CRO-SL algorithm and the mechanisms to include substrate layers are well-reported in reference [19]. The main steps of the CRO algorithm have been detailed in Table 2.

\subsection{Substrate Layers Implemented}

Though different search strategies can be defined at the practitioner's discretion, this work adopts a five-substrate construct of the CRO-SL. They are briefly described below:

1. HS: Mutation using the Harmony Search procedure. Harmony Search [28] is a well-known meta-heuristic based on the how a music orchestra improvises a melody. HS substrate controls the generation of new larvae in one of the following ways: (i) with a probability $\operatorname{HMCR}$ in $(0,1)$ (Harmony Memory Considering Rate), the value of a component of the new solution is drawn uniformly from the same values of the component in other corals of the current reef; and (ii) with a probability PAR in $(0,1)$ (Pitch Adjusting Rate), where small adjustments are applied to the values of the current solution.

2. DE: Differential Evolution algorithm mutation. This substrate is based on the DE algorithm defined in reference [29]. This approach introduces a differential mechanism for exploring the search space. In this case, new larvae are generated by perturbing the current larva by using a vector of differences between two individuals in the population. This perturbation is defined as $\mathrm{x}^{\prime}{ }_{\mathrm{i}}=\mathrm{x}^{1}{ }_{\mathrm{i}}+\mathrm{F}\left(\mathrm{x}^{2}{ }_{\mathrm{i}}-\mathrm{x}^{3}{ }_{\mathrm{i}}\right)$ (where $\mathrm{F}$ stands for a weighting the perturbation amplitude, 0.6 in this case). After this perturbation of the current larva, the perturbed vector $x^{\prime}$ is in turn combined with an alternative (different) coral in the reef, by means of a classical 2-points crossover, as defined next.

3. 2Px: Classical two-points crossover. The crossover operator is the most used operator for exploring the search space in evolutionary computation algorithms [30]. It consists of coupling two individuals at random, and then, after choosing two points for the crossover, interchanging the genetic material in between these two points. In the current CRO-SL implementation, one larva to be crossed comes from the $2 \mathrm{Px}$ substrate, whereas the other can be chosen from any part of the reef.

4. GM: Gaussian Mutation. We consider a traditional Gaussian mutation of the form $x^{\prime}{ }_{i}=x_{i}+$ $\mathrm{N}_{\mathrm{i}}\left(0, \sigma^{2}\right)$, where $\mathrm{N}_{\mathrm{i}}\left(0, \sigma^{2}\right)$ is a random number following the Gaussian distribution of 0 mean and variance $\sigma^{2}$. We introduce a linear decreasing of $\sigma$ value during the algorithm, from $0.2(\mathrm{~A}-\mathrm{B})$ to $0.02(\mathrm{~A}-\mathrm{B})$, where $[\mathrm{B}, \mathrm{A}]$ is the domain search. Note that this procedure produces a stronger mutation in the beginning of the algorithm, and a fine tuning of the search with smaller displacements nearing the end or the algorithm's evolution.

5. SAbM: Strange Attractors-based Mutation. This is a new search operator proposed in reference [31], specifically designed to use fractal geometric patterns in the search of new larvae. Specifically, it is designed to generate structures of non-linear dynamical systems with chaotic behavior [32]. Interested reader may consult reference [31] to obtain more information on this operator.

\subsection{Objective Function: Antenna Simulation and Calculation}

The objective function considered $(f(x))$ to guide the algorithm toward optimal antenna optimization and takes into account different design requirements of the device, such as its resonant frequency and bandwidth. Specifically, in order to calculate $f(x)$, we first take into account a discretization of the $S_{11}$ antenna parameter, which is calculated by simulation using the CST software, as described in the next subsection. In this case, a discretization in steps of $2 \mathrm{MHz}$ is considered. To calculate $f(x)$, several frequency bands for mobile communication systems (including LTE and 5G) has been considered. For each frequency band, the mathematical formulation of the objective function is the following:

$$
g_{f}(x)=0.8 \cdot N^{-10 d B}+0.1 \cdot M+0.1 \cdot M^{*}
$$


where $N^{-10 \mathrm{~dB}}$ stands for the number of $\mathrm{S}_{11}$ points in the observation window under $-10 \mathrm{~dB}, M=$ $\mid$ mean $\left(\mathrm{S}_{11}\right)\left|, M^{*}=\right| \min \left(\mathrm{S}_{11}\right) \mid$ and $\mathrm{f}$ stands for a given selected frequency band. The final objective function value $f(x)$ is obtained by adding the value of $g_{f}(x)$ for all the frequency bands $\mathrm{f}$ considered:

$$
f(x)=\sum_{f} g_{f}(x)
$$

Note that this function takes into account the antenna bandwidth for all the frequency bands considered, the resonant frequency, and the actual value of the antenna reflection coefficient. In order to make the calculation, we define a measurement window at each selected frequency band, with a resolution of 20MHz: (1) $f_{1}=791-870 \mathrm{MHz}(5 \mathrm{G})$; (2) $f_{2}=1.7-2.3 \mathrm{GHz}$ (LTE); (3) $f_{3}=3.3-3.8 \mathrm{GHz}(5 \mathrm{G})$. Note that these frequency bands cover the majority of communications services such as $2 \mathrm{G} / 3 \mathrm{G} / 4 \mathrm{G}$ and also LTE and $5 \mathrm{G}$ bands of ultimate mobile communication systems.

\section{Antenna Simulation with CST Software}

CST Microwave Studio@ ( from Dassault Systèmes SE (France) is a well-known software package for electromagnetic analysis and simulation in the high frequency range. It is able to provide a fully automatic meshing procedure of any electromagnetic device and its simulation using different possible simulation techniques, depending on the case (transient solver, frequency domain solver, integral equation solver, etc.). The idea is to launch the antenna simulation for each solution encoded in the CRO-SL algorithm (a given antenna design). The CRO-SL has been coded in Matlab, and we are able to call the CST simulation directly from Matlab, so the hybridization of the CRO-SL and the CST software for antenna simulation is direct. Figure 2 shows this hybridization process: the CST software is launched in order to simulate each larva (antenna design) in the CRO-SL. After the antenna simulation, we calculate the value of the objective function associated with the simulated antenna using Equations (1) and (2), and this value is used in the evolution of the CRO-SL algorithm.

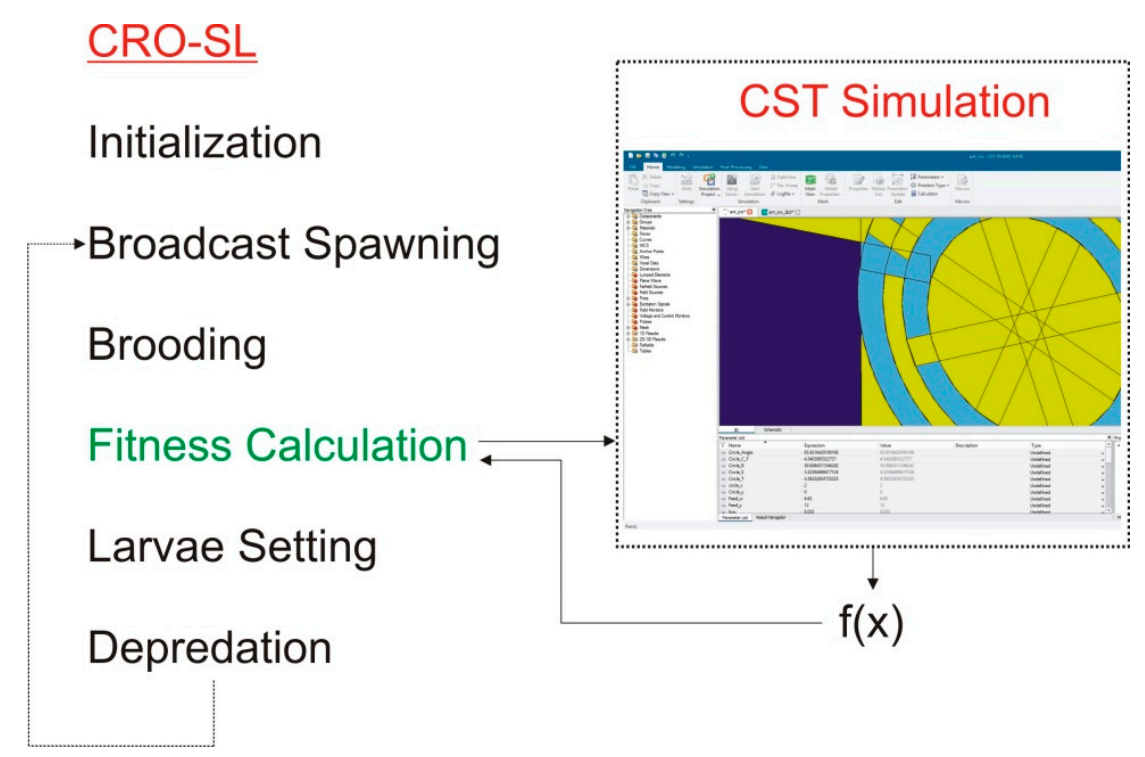

Figure 2. Hybridization of the CST simulation software with the Coral Reefs Optimization with Substrate Layer (CRO-SL) for optimized the parameters of the proposed antenna.

\section{Computational Evaluation and Results}

This section presents the computational evaluation of the proposed antenna, by means of several simulations using the CRO-SL and CST software. In the first experiment carried out, we consider the highest two frequency bands $\left(f_{2}\right.$ and $f_{3}$, associated with LTE and 5G mobile communication 
systems). In this case, the CRO-SL algorithm is able to obtain a good solution for the problem, within 50 generations, as can be in the $S_{11}$ antenna parameter obtained (Figure 3), with peaks under $-10 \mathrm{dBs}$ in both frequency bands considered. The best solution (antenna) obtained by the CRO-SL is shown in Figure 4 (front and bottom view). In this case, the fitness evolution followed by the CRO-SL is shown in Figure 5. The CRO-SL performance depends on how the different substrates operate for this problem. Figure 6 shows the percentage of best solutions and the number of solutions got into the reef for the different substrates. This is a good indication of the best substrates for this specific optimization problem. In this case, the GM substrate is the most active substrate in the CRO-SL to obtain good solutions for the problem, followed by the SAbM and 2Px operators.

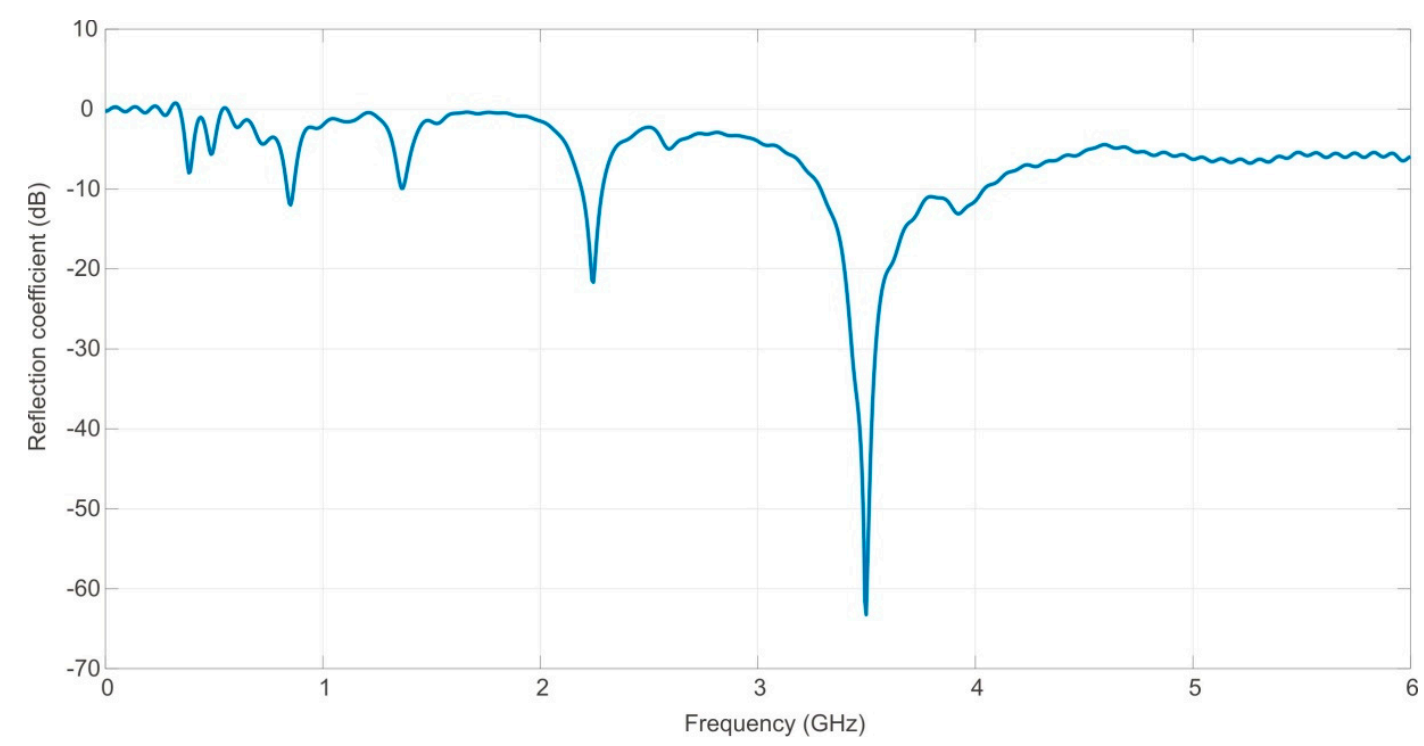

Figure 3. Reflection coefficient of the proposed antenna optimized for $f_{2}$ and $f_{3}$ frequency bands.

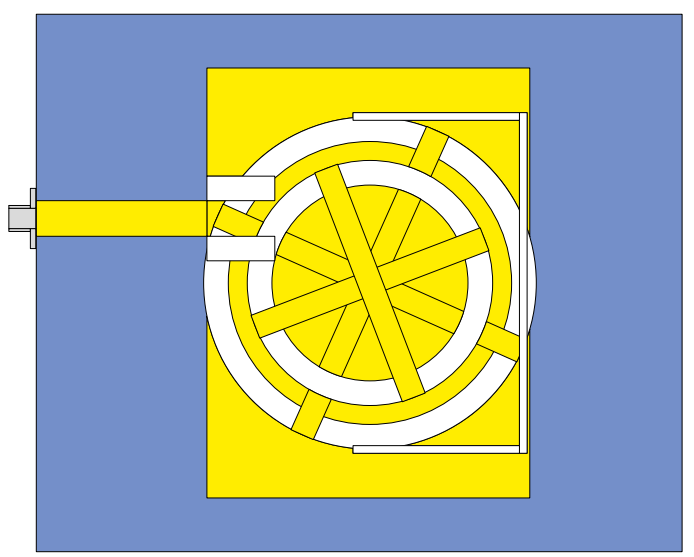

(a)

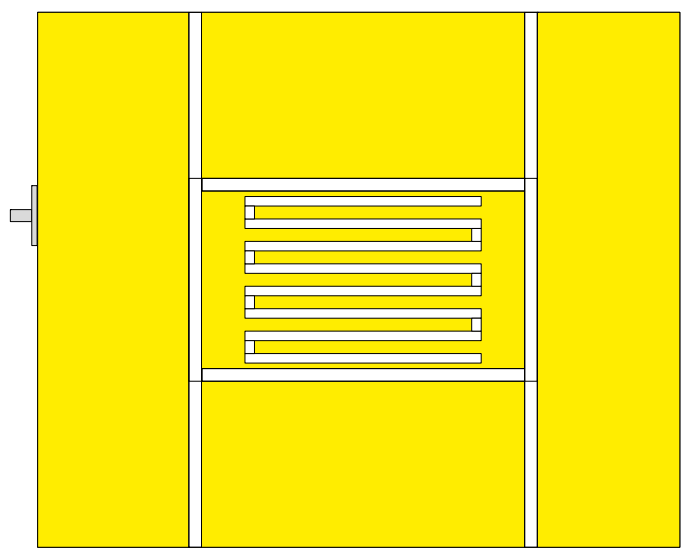

(b)

Figure 4. Final antenna layout for the two-frequency bands optimization case, after the optimization process. (a) Front view; (b) bottom view. 


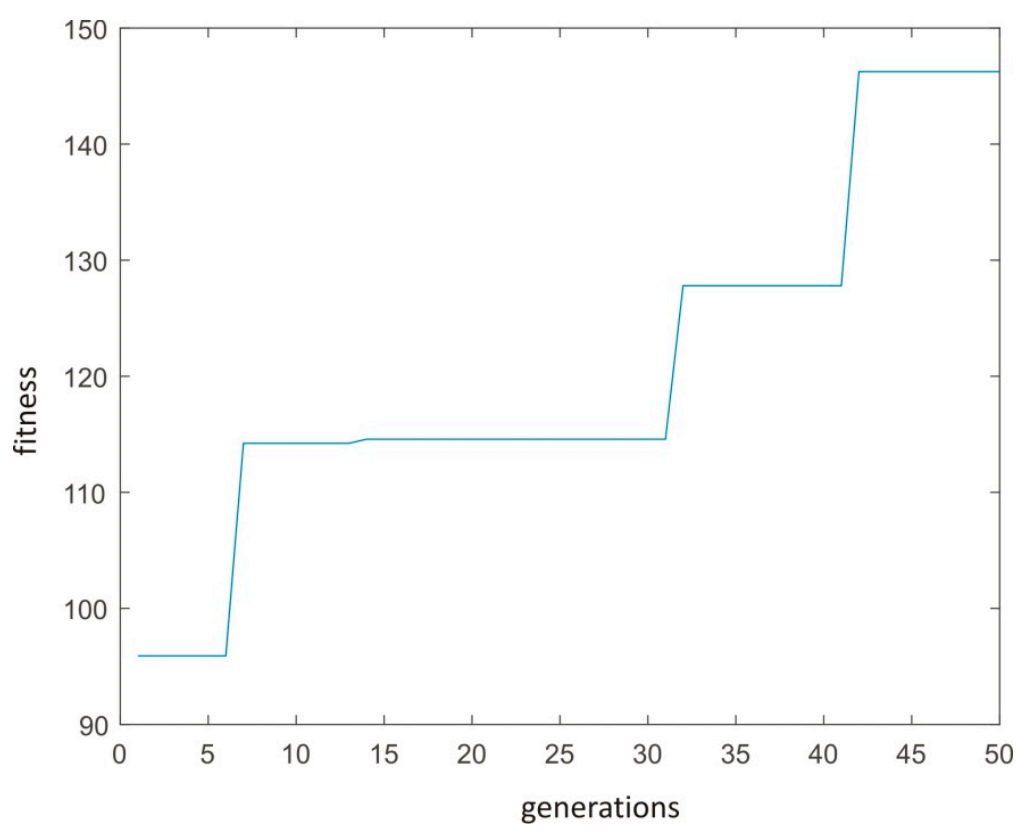

Figure 5. Evolution of the CRO-SL fitness (Equation (2)) in two frequency bands antenna optimization process.

The design of the antenna with the CRO-SL considering the three frequency bands for LTE and 5G has been carried out using the solution for the two frequencies shown above as initial point. In order to do this, we include the best solution for the two-frequencies case into the initial population of the CRO-SL, completing it with randomly-generated solutions and a number of variations of the two-frequencies case obtained by mutation of the best solution. With this, the evolution of the CRO-SL towards a high-quality antenna, able to respond in the three frequency bands considered was really fast. Figure 7 shows the $S_{11}$ antenna parameter obtained by the CRO-SL. Note that the solution obtained is extremely good. In Figure $7 \mathrm{a}$, it is possible to visualize three peaks under $-25 \mathrm{dBs}$ in the three frequency bands, with a peak under $-45 \mathrm{~dB}$ in the $5 \mathrm{G}$ frequency centered in $3.5 \mathrm{GHz}$, and good bandwidth associated with all the frequencies considered. In the same way, the results represented in Figure $7 \mathrm{~b}$ confirm the good performance of the optimized antenna. Please note that the markers on Figure $7 \mathrm{~b}$ show the center frequency for each service, but not the exact resonant frequency.

To further evaluate the performance of the CRO-SL algorithm, the optimization problem with three bands has been also tackled with an Evolutionary Algorithm. The initial parameters of the EA are the same as the $\mathrm{CRO}$ (population size and number of iterations) in order to be fully comparable. Table 3 shows the comparison between the CRO-SL algorithms and an Evolutionary algorithm. This table shows the best objective function obtained by each compared algorithm (CRO-5SL optimizing two bands, CRO-5SL optimizing three bands, and EA optimizing three bands). It can be seen that the CRO reach a better solution than the EA even when it is optimizing juts two frequency bands. 


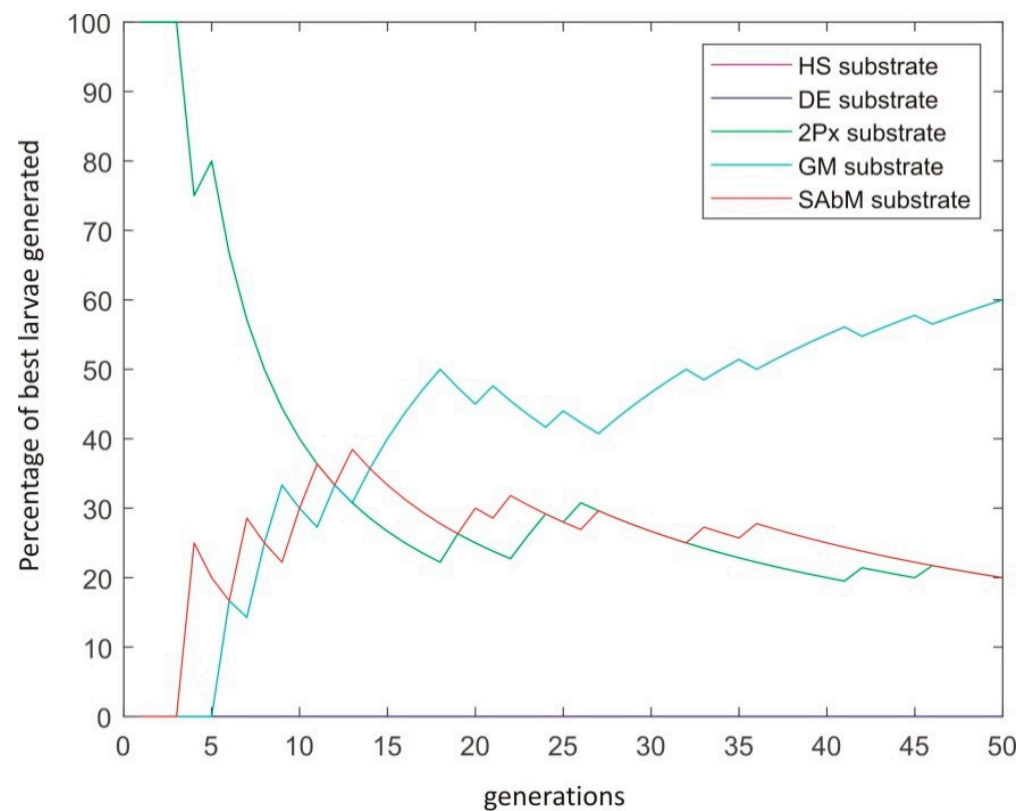

(a)

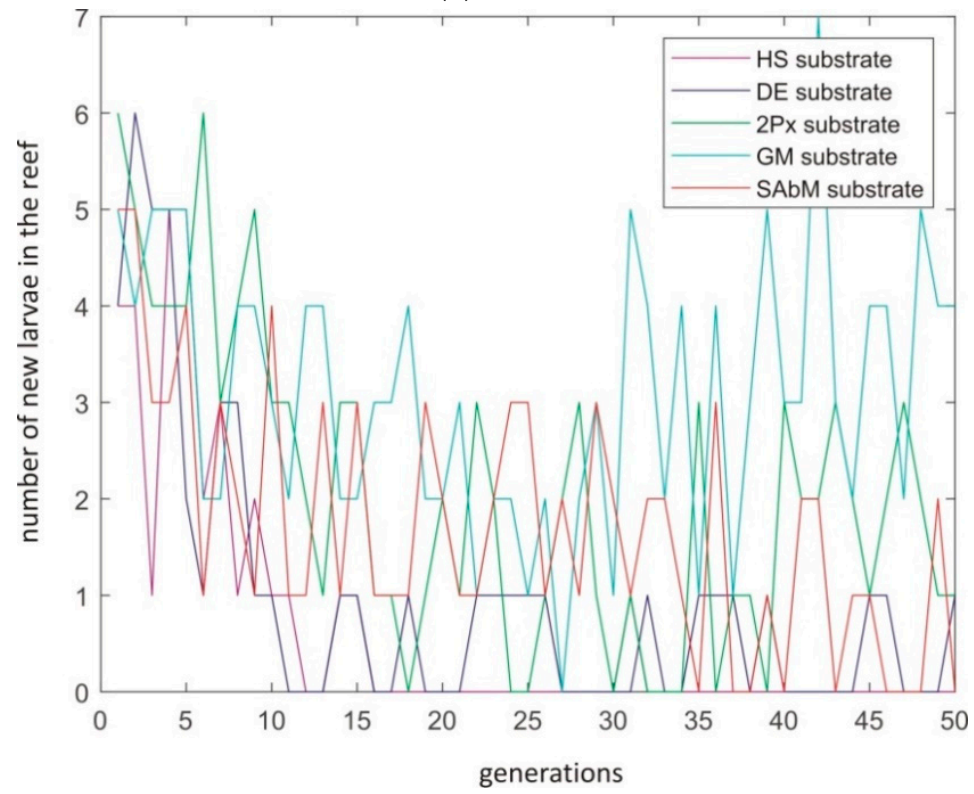

(b)

Figure 6. CRO-SL substrate performance metrics for the two-frequencies antenna optimization. (a) Best substrate for larvae generation; (b) best substrate for getting larvae into the reef. 


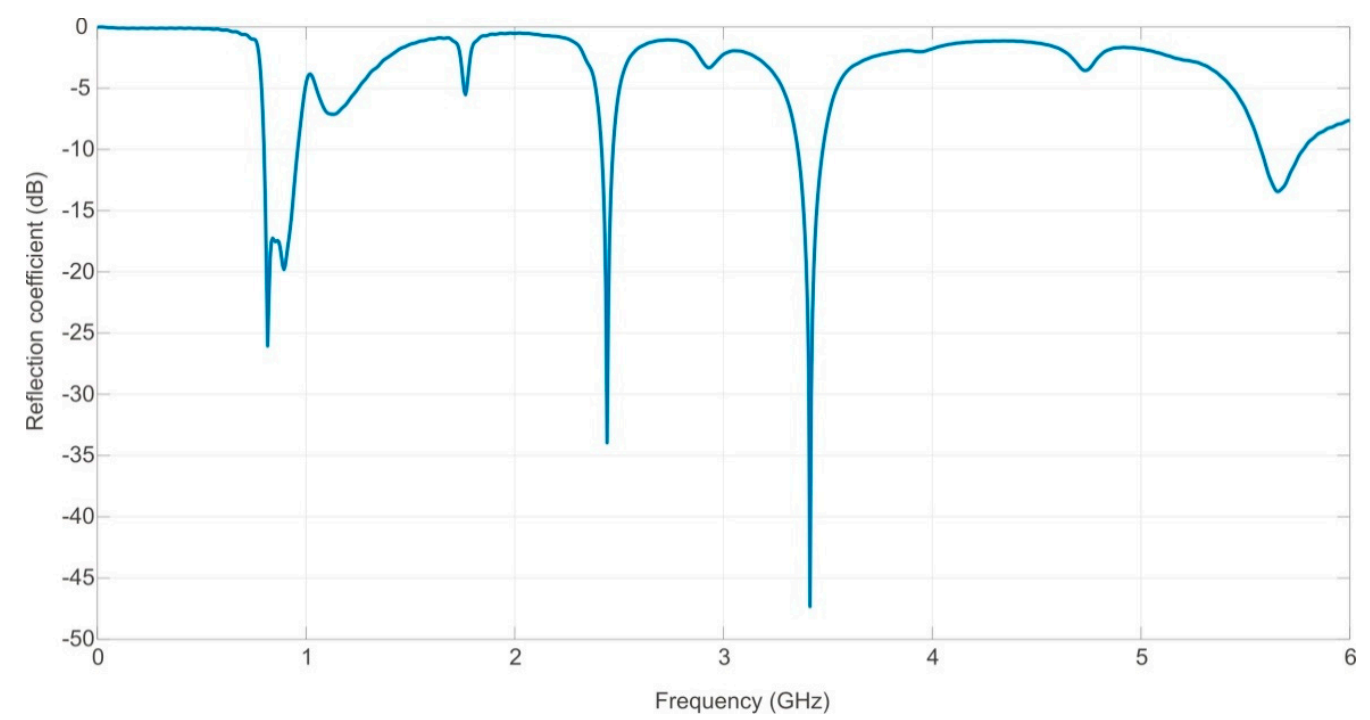

(a)

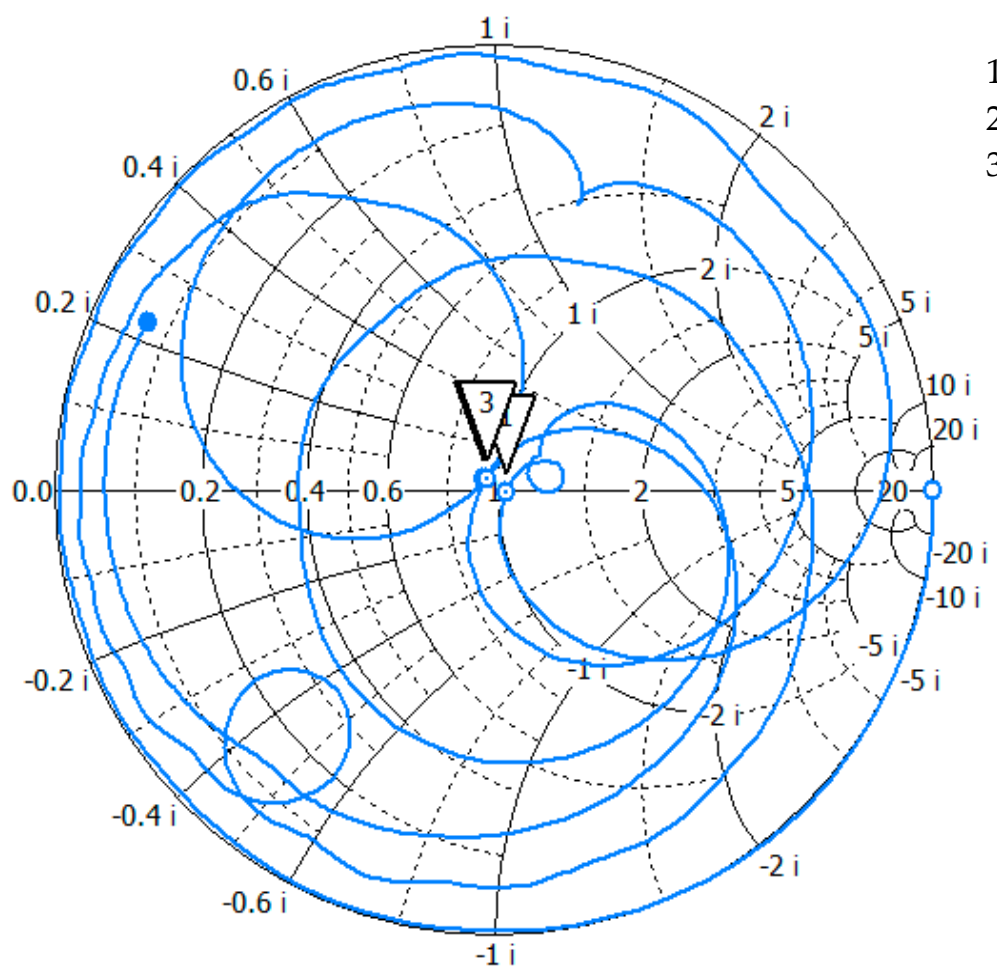

1. f1, (55.72-0.92j)

2. $\mathrm{f} 2,(47.26+2.1 \mathrm{j})$

3. f3, $(48.38+2.2 \mathrm{j})$

(b)

Figure 7. Reflection coefficient of the proposed antenna optimized for $f_{1}, f_{2}$ and $f_{3}$ frequency bands. (a) Reflection coefficient in $\mathrm{dB}$; (b) reflection coefficient in Smith Chart. 
Table 3. Comparison of the best results obtained by the proposed CRO-SL approaches and an evolutionary algorithm.

\begin{tabular}{cc}
\hline Algorithm & Best Fitness \\
\hline CRO-SL (two frequency bands) & 146.24 \\
CRO-SL (three frequency bands) & 155.03 \\
Evolutionary Algorithm & 130.05 \\
\hline
\end{tabular}

Figure 8 shows the final antenna layout obtained with the CRO-SL algorithm when the three frequency bands are considered. As can be seen after a comparison with the two-frequency bands case, the obtained antenna for the three frequency band shows a more reduced Circle $\mathrm{R}$ characteristic, with a wider U_T. There are also differences in the back-side of the optimized antenna (meanders design) when compared to the two-frequencies case.

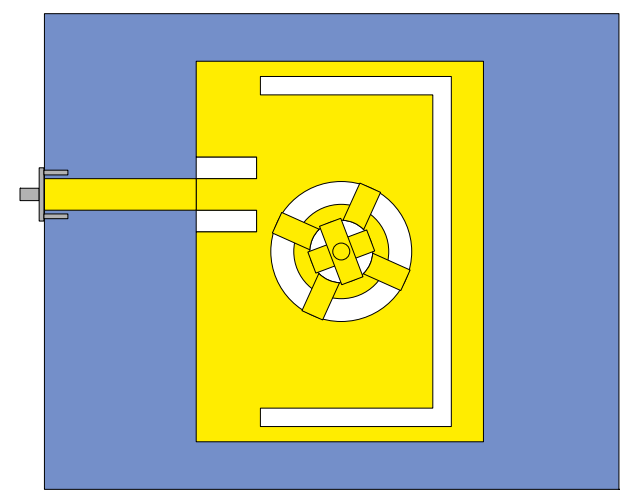

(a)

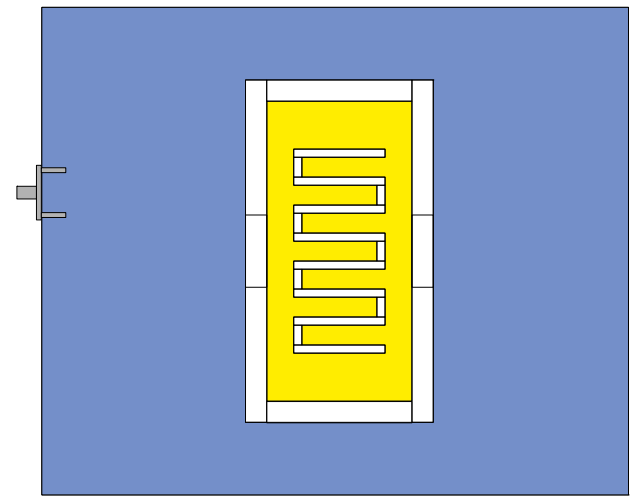

(b)

Figure 8. Final antenna layout for the three-frequency bands optimization case, after the optimization process; (a) Front view; (b) Bottom view.

Figure 9 shows the surface current distribution of the antenna for 800,2400 , and $3500 \mathrm{MHz}$ bands. As can be seen, the surface current is concentrated around the U slot for the lower band. In the upper band, the higher values are concentrated around the square patch. The current distribution in the middle band is mainly located in the feeding line and the annular patch. The influence of the ground plane meanders and slots is also shown in the figure.

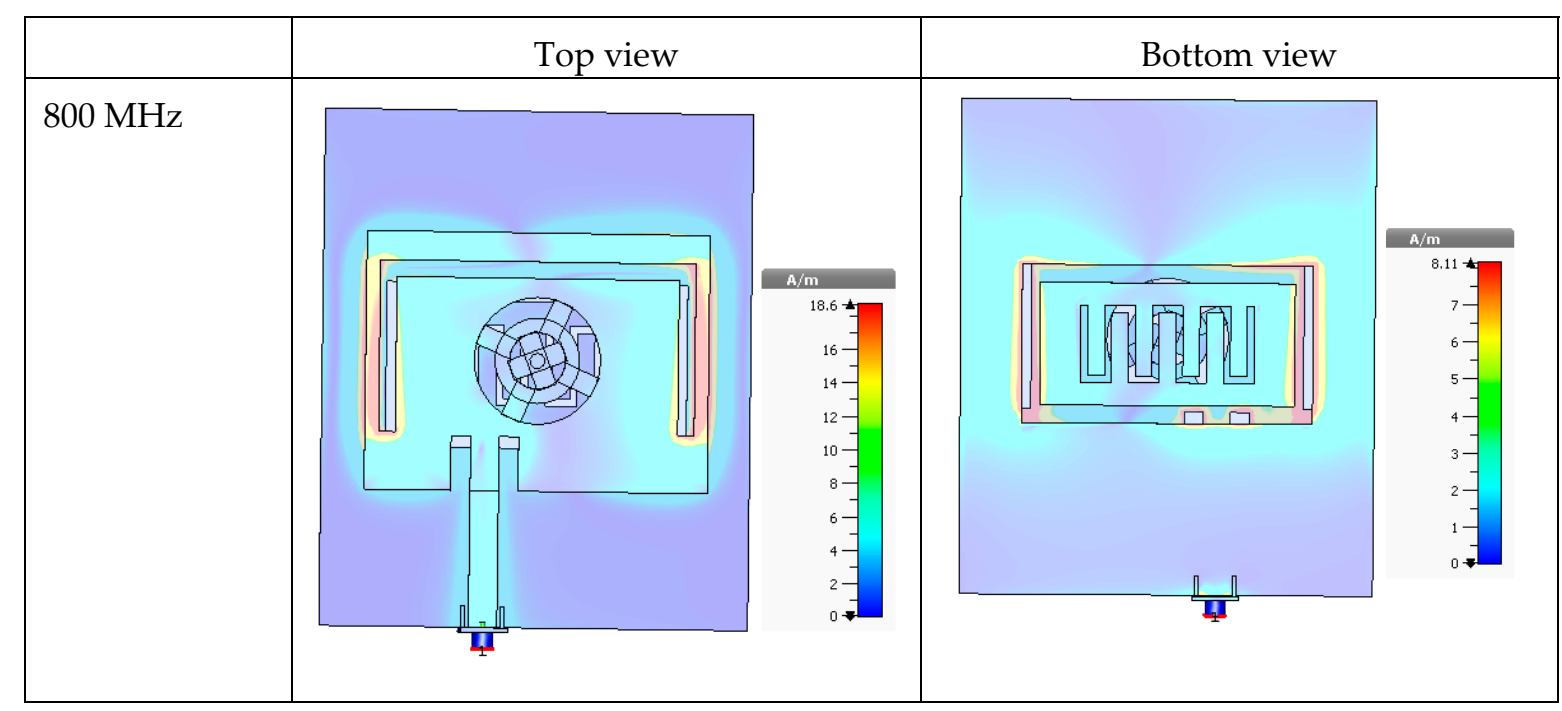

Figure 9. Cont. 


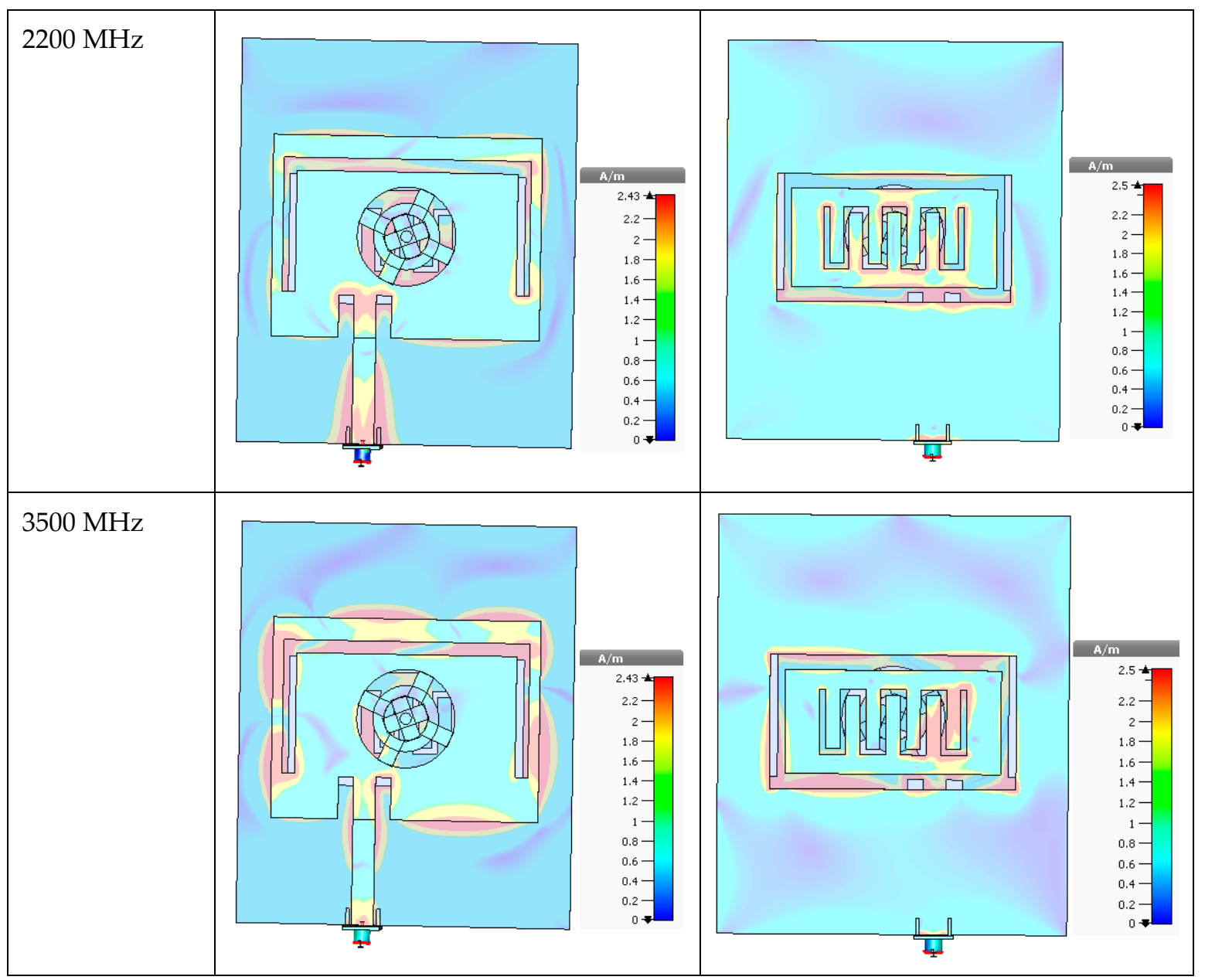

Figure 9. Surface current distribution for the antenna obtained in the three-frequency bands optimization case.

Radiation patterns and gain values for the antenna are given in Figure 10 and Table 4. At $800 \mathrm{MHz}$, the results are similar to the basic U slot antenna, as the current distribution is mainly located around it and also, the meanders and slots in the ground plane do not affect specially in this case. For the rest of the cases, the radiation pattern differs from the basic equivalent antennas, i.e., annular patch or square patch because neither a single element is involved nor the ground plane influence is negligible.
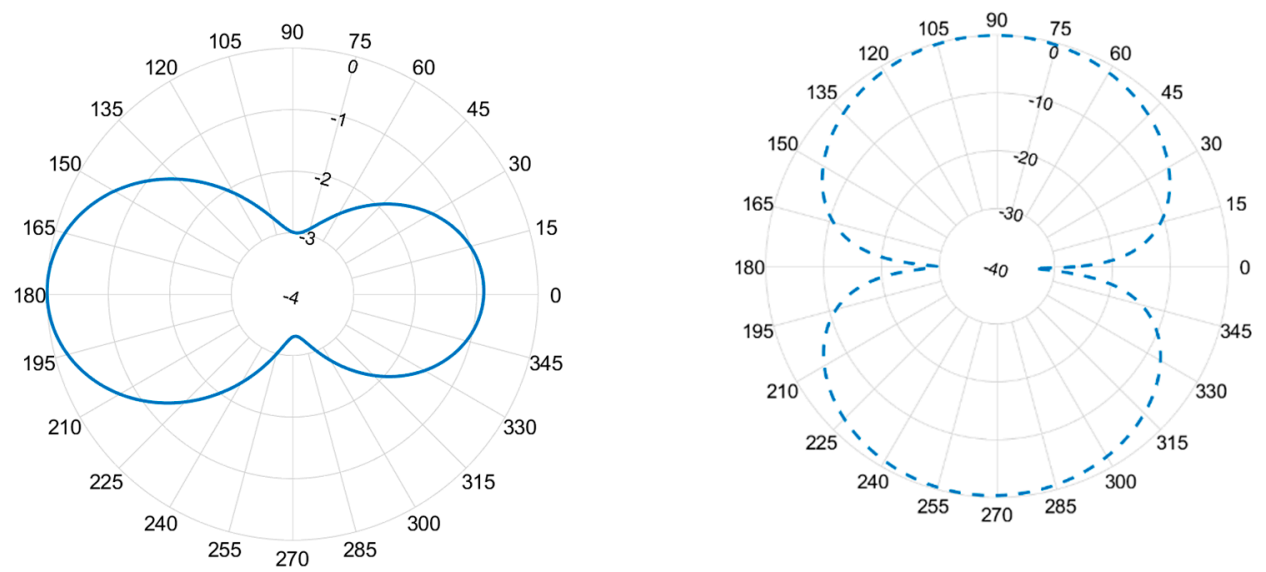

(a)

Figure 10. Cont. 

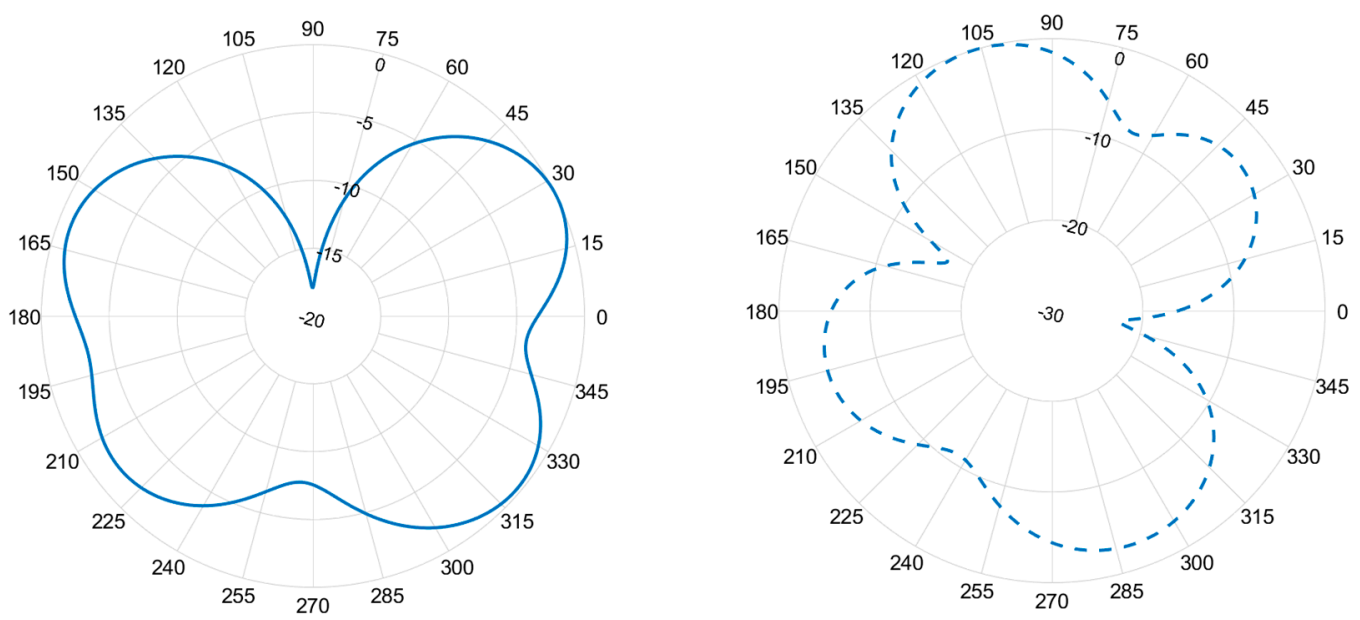

(b)
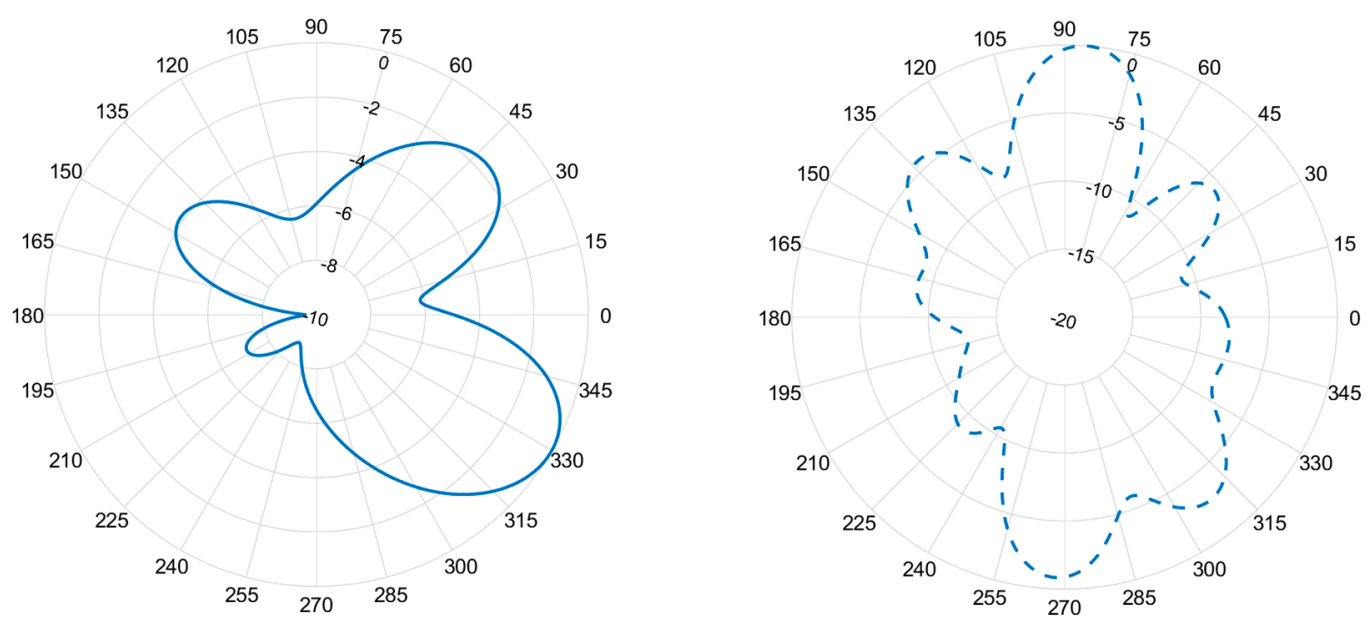

(c)

Figure 10. Final antenna radiation pattern; (a) plane E and plane $\mathrm{H}$ at $800 \mathrm{MHz}$; (b) plane $\mathrm{E}$ and plane $\mathrm{H}$ at $2.2 \mathrm{GHz}$; (c) plane $\mathrm{E}$ and plane $\mathrm{H}$ at $3.5 \mathrm{GHz}$.

Table 4. Gain (dBi) for the antenna obtained in the three-frequency bands optimization case.

\begin{tabular}{cc}
\hline Frequency $\mathbf{( G H z )}$ & Gain $(\mathbf{d B i})$ \\
\hline 0.8 & 2.734 \\
2.2 & 4.793 \\
3.5 & 8.344 \\
\hline
\end{tabular}

The performance of the CRO-SL algorithm in this problem is shown in Figure 11 (fitness evolution), and Figure 12 performance metrics for the different substrates of the CRO-SL. Again, the GM is the most active operator in improving the searching capabilities of the algorithm. The SAbM and the $2 \mathrm{Px}$ are also important in the last stages of the algorithm, both in generating good larvae and when the inclusion of the solutions into the reef is considered. 


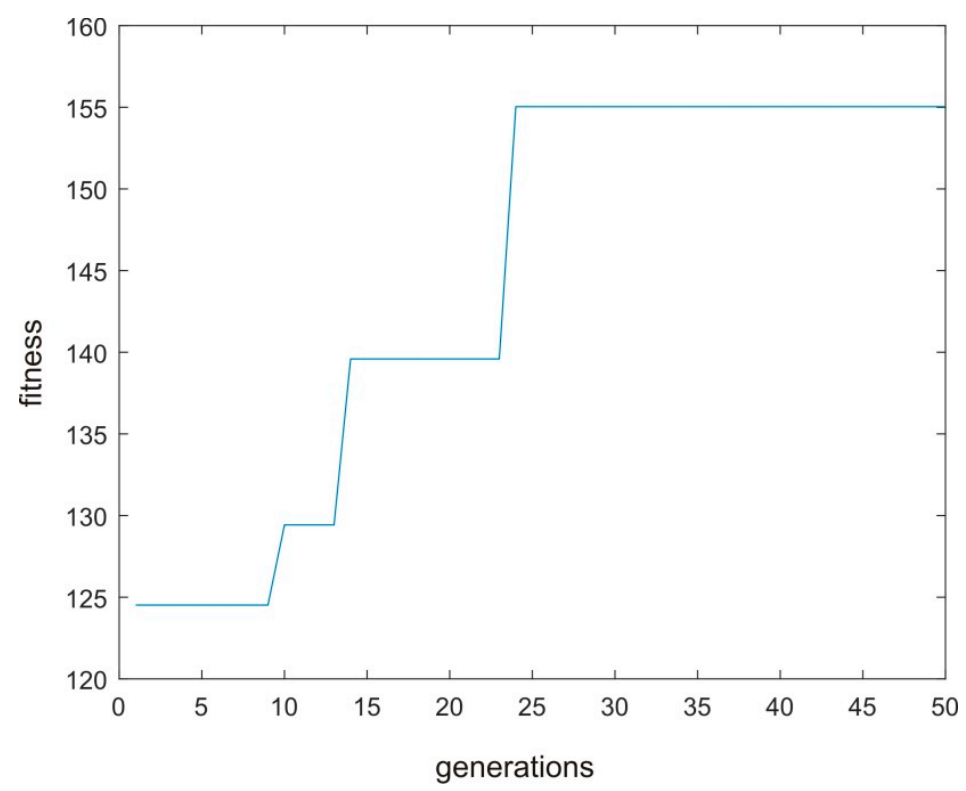

Figure 11. Evolution of the CRO-SL fitness (Equation (2)) in the three-frequency bands antenna optimization process.

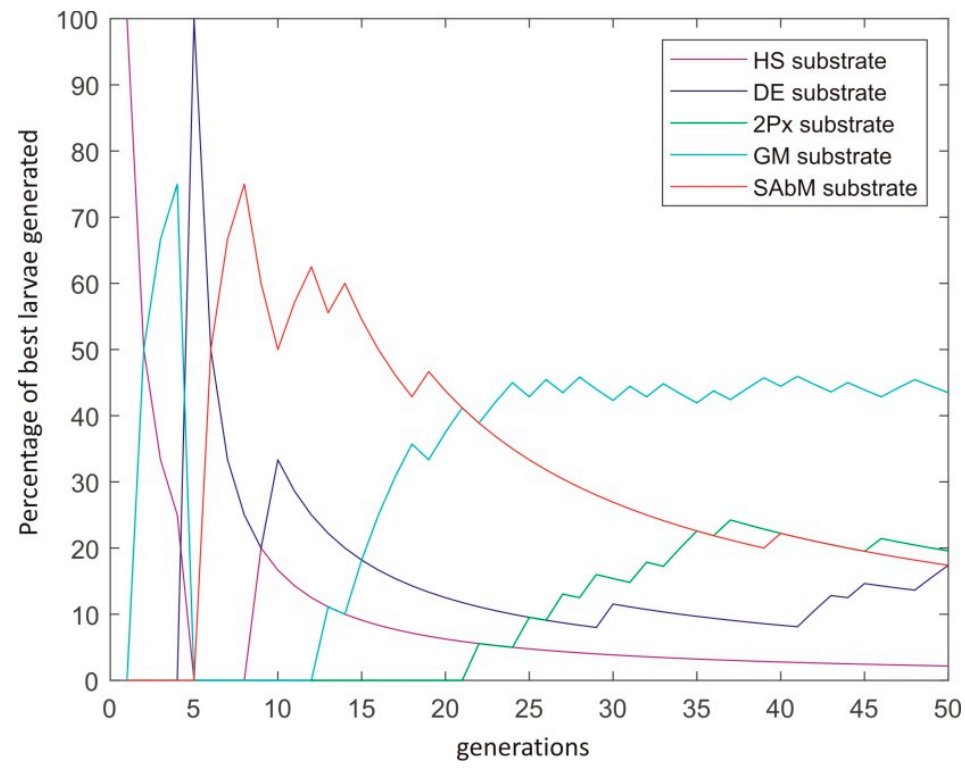

(a)

Figure 12. Cont. 


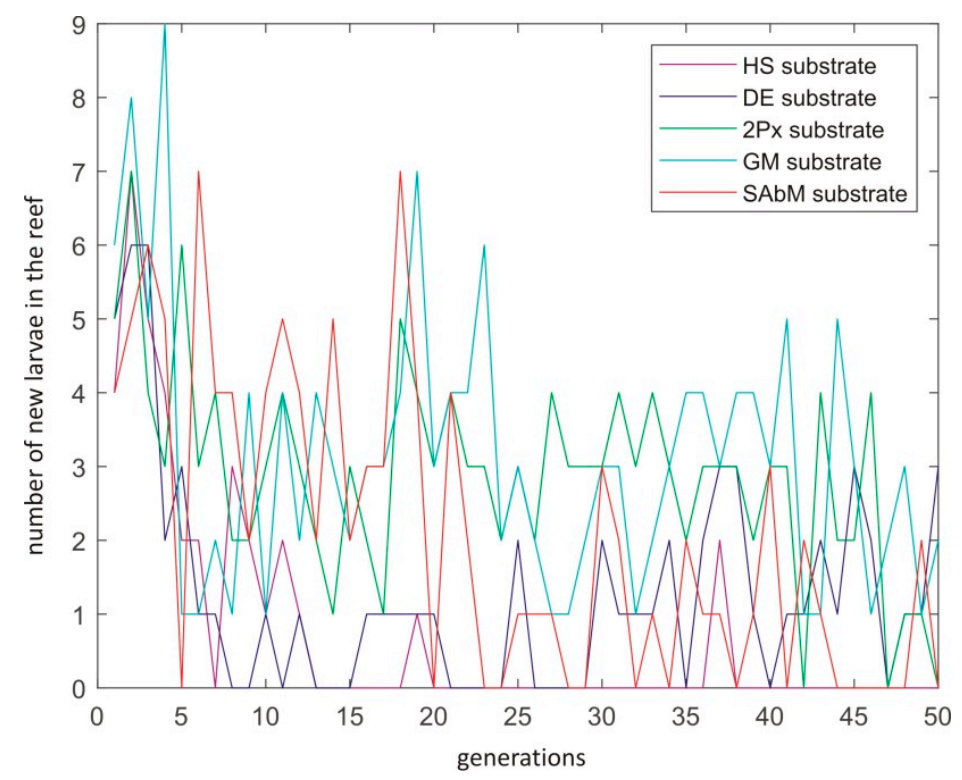

(b)

Figure 12. CRO-SL substrate-performance metrics for the two-frequencies antenna optimization; (a) Best substrate for larvae generation; (b) Best substrate for getting larvae into the reef.

Here, we have shown how we are able to optimize a multi-band microstrip textile patch antenna, with capabilities in $5 \mathrm{G}$ services, with the CRO-SL algorithm. The obtained device after the optimization is a robust antenna, able to operate in the three frequency bands considered $(850 \mathrm{MHz}, 2.2 \mathrm{GHz}$ and $3.5 \mathrm{GHz}$ ), where communication services such as $5 \mathrm{G}$ operate. The results shown for the two-frequencies and three-frequencies cases optimization shown that we are able to obtain a small textile antenna with extremely good capabilities in the desired frequency bands.

\section{Conclusions}

In this paper, we have presented the optimization of a textile multi-band antenna, considering LTE and 5G frequency bands. The optimized device is composed by a rectangular microstrip patch with two concentric annular slots, a U-Shaped slot, and three sleeved meanders in the ground plane. This novel form makes the antenna optimization very hard, since its layout depends on a number of design variables, and the antenna must be simulated in order to obtain an optimization result. Thus, traditional optimization methods are not applicable, and meta-heuristics algorithms are the best option. In this case, we propose a novel ensemble-based algorithm-the CRO-SL, a kind of evolutionary algorithm able to combine different search operators within a single population of possible solutions to the problem. The objective function which guides the evolution of the algorithm is obtained after the antenna simulation with a specific simulation software for electromagnetic analysis in the high frequency range. In the experimental evaluation of the proposed method, we have shown the design of two different kind of antennas for two and three frequency bands, both including $5 \mathrm{G}$ frequencies. In both cases, the CRO-SL algorithm is able to obtain designs with a high performance in the required frequency bands, as shown in the S11 antenna parameter obtained. The textile antennas designed have a small size (around $60 \mathrm{~mm}$ ), and the antenna substrate would allow their inclusion in different types of fabrics or clothes, providing them with LTE and 5G capacity connection.

Author Contributions: R.S.-M., D.M.-V., and P.-L.L.-E. performed the simulations, built the platform to connect the software to do the optimization with the electromagnetic simulation tool. C.C.-G. and S.S.-S. designed and adjusted the optimization algorithm. All the authors have contributed to writing and reviewing the paper. All authors have read and agreed to the published version of the manuscript.

Funding: This work has been partially supported by the Spanish Ministerial Commission of Science and Technology (MICYT) through project number TIN2017-85887-C2-2-P. 
Conflicts of Interest: The authors declare no conflict of interest.

\section{References}

1. Panwar, N.; Sharma, S.; Singh, A.K. A survey on 5G: The next generation of mobile communication. Phys. Commun. 2016, 18, 64-84. [CrossRef]

2. Locher, I.; Klemm, M.; Kirstein, T. Troster. Design and characterization of purely textile patch antennas. IEEE Trans. Adv. Packag. 2006, 29, 777-788. [CrossRef]

3. Hertleer, C.; Hendrik, R.; Vallozzi, L.; van Langenhove, L. A textile antenna for off-body communication integrated into protective clothing for firefighters. IEEE Trans. Antennas Propag. 2009, 57, 919-925. [CrossRef]

4. Dierck, A.; Agneessens, S.; Declercq, F.; Spinnewyn, B.; Stockman, G.J.; Van Torre, P.; Vallozzi, L.; Ginste, D.V.; Vervust, T.; Vanfleteren, J.; et al. Active textile antennas in professional garments for sensing, localization and communication. Int. J. Microw. Wirel. Technol. 2014, 6, 331-341. [CrossRef]

5. Lemey, S.; Agneessens, S.; van Torre, P.; Baes, K.; Vanfleteren, J.; Rogier, H. Wearable flexible lightweight modular RFID tag with integrated energy harvester. IEEE Trans. Microw. Theory Tech. 2016, 64, 2304-2314. [CrossRef]

6. Bayram, Y.; Zhou, Y.; Shim, B.S.; Xu, S.; Zhu, J.; Kotov, N.A.; Volakis, J.L. E-textile conductors and polymer composites for conformal lightweight antennas. IEEE Trans. Antennas Propag. 2010, 58, 2732-2736. [CrossRef]

7. Tak, J.; Lee, S.; Choi, J. All-textile higher order mode circular patch antenna for on-body to on-body communications. Microw. Antennas Propag. 2015, 9, 576-584. [CrossRef]

8. Liu, F.-X.; Kaufmann, T.; Xu, Z.; Fumeaux, C. Wearable applications of quarter-wave patch and half-mode cavity antennas. IEEE Antennas Wirel. Propag. Lett. 2015, 14, 1478-1481. [CrossRef]

9. Lee, H.; Jinpil, T.; Jaehoon, C. Wearable Antenna Integrated into Military Berets for Indoor/Outdoor Positioning System. IEEE Antennas Wirel. Propag. Lett. 2017, 16, 1919-1922. [CrossRef]

10. Sanchez-Montero, R.; Salcedo-Sanz, S.; Portilla-Figueras, J.A.; Langley, R. Hybrid PIFA-patch antenna optimized by evolutionary programming. Prog. Electromagn. Res. 2010, 108, 221-234. [CrossRef]

11. Das, A.; Mandal, D.; Ghoshal, S.P.; Kar, R. Concentric circular antenna array synthesis for side lobe suppression using moth flame optimization. AEU Int. J. Electron. Commun. 2018, 86, 177-184. [CrossRef]

12. Ustun, D.; Akdagli, A. Design of band notched UWB antenna using a hybrid optimization based on ABC and DE algorithms. AEU Int. J. Electron. Commun. 2018, 87, 10-21. [CrossRef]

13. Sanchez-Montero, R.; Camacho-Gomez, C.; Lopez-Esp1, P.L.; Salcedo-Sanz, S. Optimal Design of a Planar Textile Antenna for Industrial Scientific Medical (ISM) 2.4 GHz Wireless Body Area Networks (WBAN) with the CRO-SL Algorithm. Sens. J. 2018, 18, 1982. [CrossRef]

14. Awl, H.N.; Abdulkarim, Y.I.; Deng, L.; Bakir, M.; Muhammadsharif, F.F.; Karaaslan, M.; Unal, E.; Luo, H. Bandwidth Improvement in Bow-Tie Microstrip Antennas: The Effect of Substrate Type and Design Dimensions. Appl. Sci. 2020, 10, 504. [CrossRef]

15. Prabhaka, H.V.; Kummuri, U.K.; Yadahalli, R.M.; Munnappa, V. Effect of various meandering slots in rectangular microstrip antenna ground plane for compact broadband operation. Electron. Lett. 2007, 43, 848-850. [CrossRef]

16. Hossa, R.; Byndas, A.; Bialkowski, M.E. Improvement of compact terminal antenna performance by incorporating open-end slots in ground plane. IEEE Microw. Wirel. Compon. Lett. 2004, 14, $283-285$. [CrossRef]

17. Zhang, Z.Y.; Fu, G.; Zuo, S.L. A miniature sleeve meander antenna for TPMS application. J. Electromagn. Waves Appl. 2009, 23, 1835-1842. [CrossRef]

18. Salcedo-Sanz, S.; del Ser, J.; Landa-Torres, I.; Gil-Lopez, S.; Portilla-Figueras, J.A. The Coral Reefs Optimization algorithm: A novel metaheuristic for efficiently solving optimization problems. Sci. World J. 2014, 739768. [CrossRef]

19. Salcedo-Sanz, S. A review on the coral reefs optimization algorithm: New development lines and current applications. Prog. Artif. Intell. 2017, 6, 1-15. [CrossRef]

20. Langley, R.; Voudouris, K.; Batchelor, J.C. Annular ring patch antennas. In Proceedings of the IEEE Colloquium on Multi-Band Antennas, London, UK, 26 October 1992; pp. 6-11.

21. Mahmoud, S.F. A new miniaturized annular ring patch resonator partially loaded by a metamaterial ring with negative permeability and permittivity. IEEE Antennas Wirel. Propag. Lett. 2004, 3, 19-22. [CrossRef] 
22. Bao, X.L.; Ammann, M.J. Compact annular-ring embedded circular patch antenna with cross-slot ground plane for circular polarization. Electron. Lett. 2006, 42, 192-193. [CrossRef]

23. Bao, X.L.; Ammann, M.J. Dual-frequency circularly-polarized patch antenna with compact size and small frequency ratio. IEEE Trans. Antennas Propag. 2007, 55, 2104-2107. [CrossRef]

24. Zhang, Y.; Hong, W.; Yu, C.; Kuai, Z.Q.; Don, Y.; Zhou, J.Y. Planar ultrawideband antennas with multiple notched bands based on etched slots on the patch and/or split ring resonators on the feed line. IEEE Trans. Antennas Propag. 2008, 56, 3063-3068. [CrossRef]

25. Lee, K.F.; Yang, S.L.S.; Kishk, A.A.; Luk, K.M. The versatile U-slot patch antenna. IEEE Antennas Propag. Mag. 2010, 100, 71-88. [CrossRef]

26. Hsieh, C.; Chiu, T.T.; Lai, C. Compact dual-band slot antenna at the corner of the ground plane. IEEE Trans. Antennas Propag. 2009, 57, 3423-3426. [CrossRef]

27. Wu, G.; Mallipeddi, R.; Suganthan, P.N. Ensemble strategies for population based optimization algorithms-A survey. Swarm Evol. Comput. 2019, 44, 695-711. [CrossRef]

28. Geem, Z.W.; Kim, J.H.; Loganathan, G.V. A new heuristic optimization algorithm: Harmony Search. Simulation 2001, 76, 60-68. [CrossRef]

29. Storn, R.; Price, K. Differential Evolution-A simple and efficient heuristic for global optimization over continuous spaces. J. Glob. Optim. 1997, 11, 341-359. [CrossRef]

30. Eiben, A.E.; Smith, J.E. Introduction to Evolutionary Computing; Springer: Berlin, Germany, 2003.

31. Salcedo-Sanz, S. Modern meta-heuristics based on nonlinear physics processes: A review of models and design procedures. Phys. Rep. 2016, 655, 1-70. [CrossRef]

32. Grassberger, P.; Procaccia, I. Characterization of strange attractors. Phys. Rev. Lett. 1983, 50, 346-349. [CrossRef]

(C) 2020 by the authors. Licensee MDPI, Basel, Switzerland. This article is an open access article distributed under the terms and conditions of the Creative Commons Attribution (CC BY) license (http://creativecommons.org/licenses/by/4.0/). 